\title{
DETERMINATION OF LEVELS OF DEATH ANXIETIES AND DEATH DEPRESSION IN PATIENT RELATIVES WHO ARE CAREGIVERS OF ONCOLOGY PATIENTS
}

Zeliha Koç*, Tuğba Kavalalı Erdoğan **, Cansu Atmaca Palazoğlu***, Zeynep Sağlam****, Sevil Masat**, İrem Ceren Koç*****

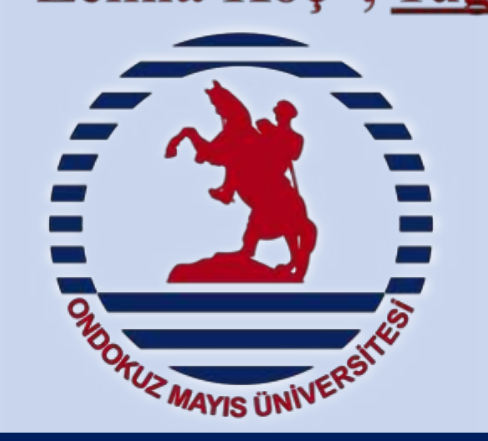

*Associate Professor, Ondokuz Mayıs University Health Science Faculty

** Research Assistant, Ondokuz Mayıs University Health Science Faculty

***MsC, Lecturer, Gümüşhane Universty Health Services Vocational School

****Lecturer, Ondokuz Mays University Health Science Faculty

$* * * *$ Student, Hacettepe University Medical Faculty

MASCC

2018

Abs 0025

\section{Introduction and Objectives}

The attitudes and reactions developed by people towards death can vary from individual to individual. This study was conducted descriptively in order determine levels of death anxieties and depression related with death in patient relatives who are caregivers of oncology patients.

\section{Methods}

This study was conducted in a university hospital between 15.01.2015 and 22.04.2015. 70 oncology patients who were receiving inpatient treatment and their relatives comprised the study group and 70 patients who were receiving inpatient treatment due to a chronic disease other than cancer and their relatives who had socio-demographical characteristics similar to those of the study group comprised the control group. Data was obtained by using a 30-question questionnaire intended for determination of socio-demographical and clinical characteristics of the patients, a 26-question questionnaire intended for determination of socio-demographical characteristics of patient relatives and Death Anxiety Scale and Death Depression Scale. In evaluation of data, percentage estimation, one-way ANOVA, Independent Sampling t test and Tukey test were used..

\section{Results and Conclusions}

Average Death Anxiety Scale score of the patient relatives in the study group was determined to be $9.0 \pm 2.6$ and average Death Anxiety Scale score of the patient relatives in the control group was determined to be $8.4 \pm 2.4$. No statistically significant difference has been determined between Death Anxiety Scale scores of the patient relatives in both study group and the control group $(\mathrm{t}=1.251 \mathrm{p}=0.215)$. Total average Death Depression Scale score of patient relatives in the control group was determined to be $10.6 \pm 2.7$ and total average Death Depression Scale score of patient relatives in the control group was determined to be 9.6 \pm 2.6 . A statistically significant difference has been determined between Death Depression Scale scores of patient relatives in both study group and the control group $(\mathrm{t}=2.062 \mathrm{p}=0.043)$. In this study, although patient relatives of oncology patients had more intensive feelings of death depression, sadness and loneliness compared to the control group, it was determined that no significant difference was present between both groups in terms of death anxiety.

Key words: Anxiety, depression, patient relative, oncology, death.

\section{Contact Information}

Tugba KAVALALI ERDOGAN

Research Assistant Ondokuz Mayis University

Health Science Institution

Samsun / TURKEY

E-mail: tugbakavalali@hotmail.com

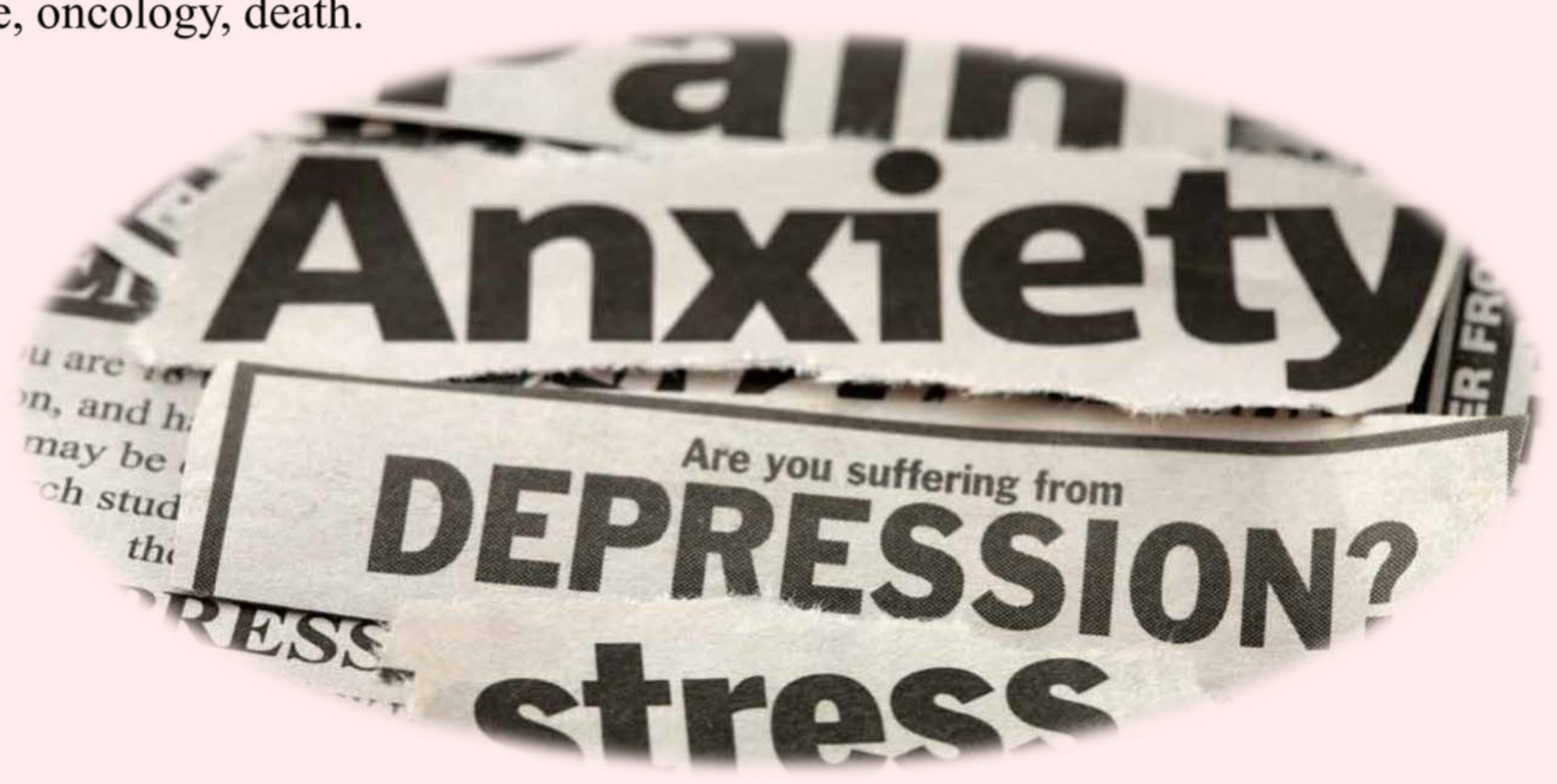

